\title{
Pola ruang natah di Desa Sibang Gede, Kecamatan Abiansemal, Kabupaten Badung, Provinsi Bali
}

\author{
Komang Teja Nugraha ${ }^{1}$, Anak Agung Gede Dalem Sudarsana ${ }^{1 *}$, Anak Agung Gede Sugiantara ${ }^{1}$
}

1. Program Studi Arsitektur Pertamanan, Fakultas Pertanian, Universitas Udayana, Indonesia 80225

*E-mail:agungdalems@gmail.com

\begin{abstract}
Space pattern of natah at Sibang Gede Village, Abiansemal District, Badung Regency, Bali Province. The growth of population in Sibang Gede Village, requires a land for the construction of the house based on the philosophy of Balinese culture concept. The extent of these needs impact on the rearrangement of space and the function of buildings and plants that make the space of Balinese traditional home pattern is not applied properly. This research aims to determine the layout and function of each buildings and plants. The method used was survey method with observation technique, interview, literature study and questionnaire distribution. From 12 banjar adat (sub-village) taken each of the four yards as sample by random sampling. The results show that $60 \%$ of the people at Sibang Gede Village still did not know the placement of buildings based on the philosophy of Balinese culture and placement of plants based on the philosophy of Balinese culture $98 \%$ of the people at Sibang Gede Village still have not applied it. The concept philosophy of Balinese culture consists of Asta Bumi, Hulu-teben as the layout concept of the buildings and Asta Dala as arrangement concept of plants layout. The recommendation that can be given is to apply the philosophy of Balinese culture concept of the space pattern of natah.
\end{abstract}

Keywords: Sibang Gede Village, space pattern of natah, the philosophy of Balinese culture

\section{Pendahuluan}

Bali memiliki adat istiadat dan budaya yang sangat kuat. Bali tidak pernah lepas dari ritual keagamaan yang dilakukan sepanjang tahun, mulai dari ritual harian dan bahkan hingga ratusan tahun. Menurut Ayadnya dan Arinasa (2004), pelaksanaan upacara yang ada di Bali berkaitan erat dengan Yadnya, yang terdiri dari Dewa Yadnya (upacara yang ditujukan kehadapan Ida Sang Hyang Widhi Wasa), Pitra Yadnya (upacara yang ditujukan kehadapan para leluhur), Rsi Yadnya (upacara yang ditujukan kehadapan para guru), Manusa Yadnya (upacara yang ditujukan kepada manusia sendiri) dan Bhuta Yadnya (upacara yang ditujukan kehadapan penguasa alam bawah). Pulau Bali juga merupakan pulau yang tidak pernah berhenti dengan pembangunan, baik itu pembangunan pura, pembangunan rumah untuk masyarakat dan pembangunan yang lainnya.

Keberadaan pembangunan tidak lepas dari budaya dan adat istiadat masyarakat Bali yang sudah ada sejak jaman dulu. Segala aspek pembangunan di Bali harus berdasarkan konsep filosofi budaya Bali yang sudah ditanamkan melalui konsep-konsep Asta Bumi, Hulu-teben dan Asta Dala. Konsep ini merupakan dasar ajaran dari Agama Hindu yang berkaitan erat dengan Taman Tradisional Bali (Sardiana dkk., 2012). Menurut Raharja (2005) secara konsep, pengertian tentang Taman Tradisional Bali sama dengan pengertian taman pada umumnya. Secara Khusus, perancangan Taman Tradisional Bali lebih menekankan pada filosofi taman. Filosofi dari Taman Tradisional Bali adalah keselarasan dan keseimbangan antara Tuhan, alam dan manusia.

Pola ruang di Bali dibagi menjadi tiga, atau lebih dikenal dengan Tri Mandala. Tri Mandala terdiri dari Utama Mandala, Madya Mandala dan Nista Mandala. Dalam Tri Mandala natah termasuk ke dalam Madya Mandala beserta bangunan-bangunan rumah. Natah merupakan lahan kosong yang dikelilingi oleh gugus bangunan dan ditanami tanaman yang memiliki makna tersendiri (Dwijendra, 2008). Natah memiliki arti yang sangat penting bagi kehidupan masyarakat Bali, karena natah merupakan cerminan kehidupan sosial masyarakat, baik sosial ekonomi, maupun sosial budaya (Putra, 2003). Natah dikatakan menarik karena natah merupakan ruang terbuka dalam pola ruang pekarangan rumah yang sarat dengan makna dan filosofi. Dalam sebuah pekarangan disusun oleh beberapa gugus bangunan, antara lain bale daja, bale dangin, bale delod, 
bale dauh, dan dapur. Rumah tinggal masyarakat tradisional Bali pada umumnya sebagaimana yang dikenal dengan tipe Bali Majapahit atau tipe dataran dan rumah Bali tipe Bali Aga atau tipe pegunungan (Suarya, 2003).

Fakta di lapangan menunjukan Desa Sibang Gede merupakan salah satu desa tipe dataran (Bali majapahit), yang terletak di Kecamatan Abiansemal, Kabupaten Badung, Provinsi Bali. Secara geografis Desa Sibang Gede berada pada ketinggian rata-rata $320 \mathrm{~m}$ dpl dengan suhu udara rata-rata $28^{\circ}$ Celcius (Data Desa Sibang Gede tahun 2016). Berkembangnya pertambahan penduduk di Desa Sibang Gede berimbas pada perubahan tata letak dan fungsi dari bangunan (hardscape) serta tata letak dan fungsi dari tanaman (softscape) yang ditanam di halaman rumah (natah) pada setiap pekarangan rumah. Bertambahnya jumlah penghuni rumah menyebabkan bertambahnya kebutuhan akan tempat tinggal. Tercatat dari tahun 2013 sampai tahun 2016 pertambahan penduduk di Desa Sibang Gede mengalami pertambahan yang cukup tinggi. Menurut data Desa Sibang Gede tercatat pada tahun 2013 jumlah penduduk hanya 3.102 jiwa dan pada tahun 2016 jumlah penduduk 5.116 jiwa atau 671 jiwa per tahun, sedangkan luas lahan untuk pemukiman hanya $495 \mathrm{~km}^{2}$ serta memiliki kepadatan penduduk sebanyak 466 jiwa/ $\mathrm{km}^{2}$. Luasnya kebutuhan ini berdampak pada perubahan tata letak dan fungsi dari bangunan dan tanaman yang menjadikan pola ruang rumah tradisional Bali tidak teraplikasikan dengan baik. Pola ruang natah di Desa Sibang Gede, Kecamatan Abiansemal, Kabupaten Badung, Provinsi Bali diangkat menjadi topik penelitian dengan tujuan mengidentifikasi tata letak dan fungsi dari bangunan serta tanaman pada pola ruang natah di Desa Sibang Gede berdasarkan filosofi budaya Bali, dan menghasilkan rekomendasi desain pola ruang natah yang baik sesuai dengan konsep filosofi budaya Bali.

2. Metode Penelitian

\subsection{Tempat dan Waktu Penelitian}

Penelitian ini dilakukan di Desa Sibang Gede, Kecamatan Abiansemal, Kabupaten Badung, Provinsi Bali, yang dilakukan selama sembilan bulan dari tahap persiapan sampai dengan penyusunan skripsi, yakni pada Bulan November 2016 sampai dengan Bulan Agustus 2017.

\subsection{Alat Penelitian}

Alat yang digunakan dalam penelitian ini, yaitu aplikasi perekam suara pada telepon genggam, kamera, printer, laptop dengan software Google Earth, AutoCAD 2013, Microsoft Word, Adobe Photoshop CS3, lembar kuisioner dan lembar wawancara.

\subsection{Metode Penelitian}

Penelitian ini menggunakan metode survei dengan teknik pengumpulan data dengan menggunakan teknik observasi dan wawancara serta menggunakan kuisioner untuk mendapatkan data primer, sedangkan data sekunder diperoleh dengan teknik studi literatur. Survei adalah penelitian dengan mengambil sampel dari satu populasi dan menggunakan kuisioner sebagai alat pengumpul data yang pokok (Morissan, 2012).

\subsection{Teknik Pengumpulan Data}

Teknik pengumpulan data yang digunakan adalah pengamatan atau observasi, penyebaran kuisioner, wawancara, dan studi pustaka. Penjabarannya sebagai berikut:

1. Observasi: observasi dalam penelitian ini dilakukan pengamatan secara langsung keadaan rumah yang memiliki pola ruang natah di Desa Sibang Gede yang diambil secara acak atau random sampling.

2. Wawancara: pada tahapan ini penulis melakukan wawancara yang dilakukan secara terbuka dengan mengadakan tanya jawab langsung kepada pihak-pihak terkait, seperti undagi (tukang), tokoh masyarakat dan sulinggih (Pendeta).

3. Kuisioner: kuisioner merupakan instrumen pengumpulan data yang dilakukan untuk memperoleh informasi dengan memberikan angket kepada 48 pemilik rumah di Desa Sibang Gede (Asumsi distribusi normal dihitungan ketika jumlah sampel mencapai 30 (Reimundo, 2014)).

4. Studi Pustaka: studi pustaka yaitu mencari data yang berhubungan dengan penelitian ini baik diperoleh dari jurnal hasil penelitian, buku-buku ilmiah, laporan penelitian, peraturan-peraturan, ketetapanketetapan dan sumber-sumber tertulis maupun media elektronik (internet).

\subsection{Jenis Data}

Penelitian menggunakan data primer dan sekunder. Data yang diperoleh dari penelitian ini didapatkan dari berbagai sumber seperti yang termuat dalam tabel berikut: 
Tabel 1. Tabel Jenis dan Sumber Data Penelitian

\begin{tabular}{|c|c|c|c|c|}
\hline \multirow{3}{*}{\multicolumn{2}{|c|}{ Jenis Data }} & \multicolumn{2}{|c|}{ Bentuk Pengambilan Data } & \multirow[t]{2}{*}{ Sumber Data } \\
\hline & & Primer & Sekunder & \\
\hline & \multicolumn{4}{|c|}{ 1. Gambaran Umum } \\
\hline & Sejarah Desa Sibang Gede & & $\sqrt{ }$ & Kepustakaan, \\
\hline & Letak Geografis Desa & & & Observasi serta Kepustakaan \\
\hline & $\begin{array}{l}\text { Sibang Gede serta Batas } \\
\text { Desa }\end{array}$ & $\sqrt{ }$ & $\sqrt{ }$ & \\
\hline & $\begin{array}{l}\text { Keadaan Penduduk Desa } \\
\text { Sibang Gede }\end{array}$ & & $\sqrt{ }$ & Kepustakaan \\
\hline \multicolumn{5}{|c|}{ 2. Pola Ruang Natah } \\
\hline & $\begin{array}{l}\text { Fungsi Bangunan dan Tata } \\
\text { Letak Banqunan }\end{array}$ & $\sqrt{ }$ & $\sqrt{ }$ & $\begin{array}{l}\text { Kuisioner, wawancara dan } \\
\text { Obeservasi serta Kepustakaan }\end{array}$ \\
\hline & $\begin{array}{l}\text { Fungsi Tanaman dan Tata } \\
\text { Letak Tanaman }\end{array}$ & $\sqrt{ }$ & $\sqrt{ }$ & $\begin{array}{l}\text { Kuisioner, wawancara dan } \\
\text { Obeservasi serta Kepustakaan }\end{array}$ \\
\hline & Rekomendasi & $\sqrt{ }$ & $\sqrt{ }$ & $\begin{array}{l}\text { Observasi dan Wawancara serta } \\
\text { Kepustakaan }\end{array}$ \\
\hline
\end{tabular}

\subsection{Metode Analisis Data}

Metode analisis data menurut Silalahi (2006) meliputi tahap pengolahan data hasil obeservasi, kuisioner dan wawancara. Metode yang digunakan adalah tabulasi, analisis spasial dan analisis deskriptif.

1. Tabulasi

Teknik tabulasi data ini digunakan untuk menghitung jumlah pilihan responden (f) dibandingkan dengan jumlah keseluruhan responden (N) ke dalam bentuk presentase (\%) dengan dikali 100 persen. Perhitungan presentase seperti dikemukakan Sudjana (2001) adalah sebagai berikut:.

$$
P=f / N \times 100 \%
$$

Keterangan:

$P=$ Presentase

$\mathrm{f}=$ Frekuensi

$\mathrm{N}=\sum$ Total Responden

2. Analisis Spasial

Analisis spasial dilakukan untuk mengukur distribusi suatu kejadian berdasarkan aspek keruangan. Analisis spasial akan menghasilkan sebuah denah hasil analisis, sesuai dengan metode analisis Tuman (2001).

\section{Analisis Deskriptif}

Analisis deskriptif digunakan untuk menganalisis data dengan cara mendeskripsikan atau menggambarkan data yang telah terkumpul tanpa bermaksud membuat kesimpulan yang berlaku untuk umum, seperti yang dikemukakan Sugiyono (2004).

\subsection{Batasan Penelitian}

Penelitian ini dilakukan pada pola ruang natah di Desa Sibang Gede, Kecamatan Abiansemal, Kabupaten Badung, Provinsi Bali yang di dalam pola ruang natah tersebut berisi mengenai tata letak dan fungsi dari bangunan serta tanaman berdasarkan konsep filosofi budaya Bali.

\section{Hasil dan Pembahasan}

\subsection{Gambaran Umum Desa Sibang Gede}

Desa Sibang Gede secara administrasi terletak $10 \mathrm{~km}$ dari Kota Kecamatan Abiansemal dan 8 km dari Ibu Kota Kabupaten Badung dengan batas-batas wilayahnya, yaitu sebelah Utara berbatasan dengan Desa Sibang Kaja, sebelah Selatan berbatasan dengan Desa Tegal dan Desa Darmasaba, sebelah Timur berbatasan dengan Desa Angantaka dan Desa Sedang, sebelah Barat berbatasan dengan Desa Tegal dan Desa Darmasaba (Monografi Desa Sibang Gede, 2016). 


\subsection{Pola Ruang Natah di Desa Sibang Gede, Kecamatan Abiansemal, Kabupaten Badung, Provinsi Bali.}

Bangunan dan tanaman merupakan pembentuk dan pelengkap dari suatu natah dalam perumahan tradisional Bali. Dalam setiap penempatan dari bangunan dan tanaman sesuai dengan konsep filosofi budaya Bali tertanam konsep-konsep yang harus diaplikasikan, bangunan sendiri dengan konsep Asta Bumi dan Huluteben, sedangkan konsep pada penempatan tanaman adalah konsep Asta Dala. Kosep-konsep ini yang membentuk pola ruang natah berdasarkan dengan konsep filosofi budaya Bali.

Konsep Asta Dala merupakan konsep yang digunakan dalam pengaplikasian penempatan tanaman sesuai dengan konsep filosofi budaya Bali. Menurut Prajoko (2012) Asta Dala dimaksudkan mengenai pengertian delapan penjuru arah mata angin dengan dewa yang berstana pada arah tersebut serta warna dari delapan arah tersebut. Penempatan tanaman disesuaikan dengan tempat, warna buah, warna batang dan warna daun dari tanaman tersebut sesuai dengan konsep Asta Dala (Ayadnya dan Arinasa, 2004). Sedangkan konsep Asta Bumi adalah konsep atau aturan tentang penataan tata letak, pembagian ruang halaman dan jarak antar bangunan baik itu dalam rumah ataupun tempat suci yang dapat membentuk suatu ruang kosong yang dihimpit oleh beberapa bangunan (Pulasari dkk., 2015). Dalam Taman Tradisional Bali, Asta Bumi digunakan sebagai konsep dan aturan yang berguna untuk membangunkan aura positif dari rumah ataupun bangunan suci. Menurut Pulasari dkk. (2015), Hulu-teben merupakan konsep atau aturan dasar untuk pembangunan dari sebuah rumah maupun tempat suci untuk Umat Hindu. Konsep ini digunakan sebagai pedoman untuk menentukan letak dari bangunan yang letaknya berada di arah Uttara atau Timur yang dikenal sebagai arah suci bagi Umat Hindu dan penempatan bangunan yang letaknya di arah Selatan maupun Barat.

Berdasarkan hasil sebaran kuisioner terdapat pemahaman masyarakat pada pola ruang natah sesuai dengan konsep filosofi budaya Bali di Desa Sibang Gede, Kecamatan Abiansemal, Kabupaten Badung, Provinsi Bali. Hasil kuisioner ini berdasarkan sebaran dari 48 sampel dari 12 banjar, yaitu empat sampel diambil dari setiap banjar secara random sampling dapat dilihat pada Tabel 2.

Tabel 2. Pemahaman Masyarakat Mengenai Pola Ruang Natah yang Sesuai dengan Konsep Filosofi Budaya Bali.

\begin{tabular}{|c|c|c|c|c|}
\hline \multirow[b]{2}{*}{ No } & \multirow[b]{2}{*}{ Aspek Pola Ruang Natah } & \multicolumn{3}{|c|}{ Jawaban } \\
\hline & & Ya & Tidak & Total \\
\hline 1 & Pemahaman tentang sikut natah & $42 \%$ & $58 \%$ & $100 \%$ \\
\hline 2 & $\begin{array}{l}\text { Pemahaman tentang tata letak dari bangunan pada natah sesuai } \\
\text { konsep filosfi budaya Bali }\end{array}$ & $40 \%$ & $60 \%$ & $100 \%$ \\
\hline 3 & $\begin{array}{l}\text { Pemahaman ukuran setiap bangunan pada pekarangan sesuai konsep } \\
\text { filosfi budaya Bali }\end{array}$ & $90 \%$ & $10 \%$ & $100 \%$ \\
\hline 4 & $\begin{array}{l}\text { Memahami fungsi dari jenis-jenis bangunan rumah sesuai konsep } \\
\text { filosofi budaya Bali }\end{array}$ & $82 \%$ & $18 \%$ & $100 \%$ \\
\hline 5 & $\begin{array}{l}\text { Perubahan tata letak dan ukuran bangunan selama } 10-20 \text { tahun } \\
\text { belakang pada pekarangan }\end{array}$ & $83 \%$ & $17 \%$ & $100 \%$ \\
\hline 6 & Pemahaman tentang tata letak dari tanaman pada natah sesuai konsep & $46 \%$ & $54 \%$ & $100 \%$ \\
\hline Laniuta & 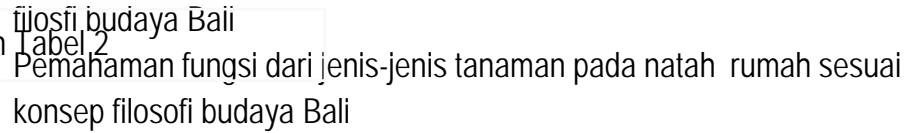 & $13 \%$ & $87 \%$ & $100 \%$ \\
\hline 8 & Penempatan tanaman sesuai dengan konsep filosofi budaya Bali & $2 \%$ & $98 \%$ & $100 \%$ \\
\hline 9 & Masih menerapkan konsep filosofi budaya Bali (Asta Bumi, Hulu-teben & $40 \%$ & $60 \%$ & $100 \%$ \\
\hline & dan Asta Dala) & & & \\
\hline 10 & $\begin{array}{l}\text { Natah berfungsi secara baik (sebagai ruang terbuka) atau tidak } \\
\text { (sebagai ruang terbuka) }\end{array}$ & $79 \%$ & $21 \%$ & $100 \%$ \\
\hline 11 & $\begin{array}{l}\text { Perlu diadakan penyuluhan tentang pola ruang natah yang sesuai } \\
\text { dengan konsep filosofi budaya Bali }\end{array}$ & $96 \%$ & $4 \%$ & $100 \%$ \\
\hline
\end{tabular}




\subsection{Pola Tata Letak dan Fungsi Bangunan pada Natah di Desa Sibang Gede, Kecamatan Abiansemal, Kabupaten Badung, Provinsi Bali.}

Dalam filosofi tersebut terdapat konsep Asta Bumi dan konsep Hulu-teben yang merupakan konsep yang digunakan untuk menentukan tata letak dan jarak dari bangunan itu sendiri yang nantinya setelah mendapatkan tata letak dan ukuran akan membentuk suatu ruang kosong yang berpusat di tengah-tengah bangunan yang disebut dengan natah (Dwijendra, 2008). Hasil penelitian menunjukan sebanyak 17\% masyarakat Desa Sibang Gede menyatakan tidak ada perubahan tata letak dan ukuran pada bangunan, yang artinya masyarakat Desa Sibang Gede masih menerapkan konsep filosofi budaya Bali, sedangkan sebanyak $83 \%$ masyarakat menyatakan adanya perubahan tata letak dan ukuran dari bangunan yang tidak sesuai dengan konsep filosofi budaya Bali, perubahan tata letak dan ukuran bangunan mengakibatkan natah yang terbentuk menjadi tidak baik dan tidak sesuai dengan filosofi budaya Bali. Banyaknya perubahan pada pola tata letak dan ukuran dari banguan diakibatkan oleh bertambahnya jumlah penghuni rumah dan minimnya lahan adalah faktor utama, maka dari itu agar tidak merubah konsep filosofi budaya Bali yang harus diterapkan pada tata letak dan ukuran dari bangunan untuk memperoleh natah yang sesuai, hendaknya bangunan tersebut harus ditingkatkan beberapa lantai dan menggunakan konsep Asta Bumi sebagai acuan untuk menentukan jarak dari bangunan satu ke bangunan yang lainnya (Bidja, 2000).

Fungsi bangunan tidak lepas dari pemahaman masyarakat akan fungsi dari setiap bangunan, sebanyak 82\% masyarakat Desa Sibang Gede menyatakan mengetahui tentang fungsi dari masing-masing bangunan yang sesuai dengan konsep filosofi budaya Bali, sedangkan sebanyak 18\% masyarakat menyatakan tidak mengetahui fungsi dari masing-masing bangunan. Sebagian besar masyarakat mengetahui fungsi dari masing-masing bangunan dikarenakan masyarakat Desa Sibang Gede telah memahami dari adatistiadat dan budaya yang telah diwariskan sejak jaman dulu.

\subsection{Pola Tata Letak dan Fungsi Tanaman pada Natah di Desa Sibang Gede, Kecamatan Abiansemal, Kabupaten Badung, Provinsi Bali.}

Dalam Konsep Asta Dala, pemilihan warna dan penempatan tanaman menjadi suatu yang sangat penting dalam taman natah, karena warna dan penempatan tanaman pada areal natah akan membentuk karakter bagi rumah itu sendiri (Ayadnya dan Arinasa, 2004). Penelitian ini menunjukan sebanyak 98\% masyarakat Desa Sibang Gede tidak melakukan penempatan tanaman sesuai konsep filosofi budaya Bali, yaitu penggunaan konsep Asta Dala, sedangkan sebanyak $2 \%$ masyarakat masih menerapkan konsep Asta Dala sebagai acuan penempatan tanaman. Kurangnya pengaplikasian konsep Asta Dala sebagai acuan penempatan tanaman dikarenakan kurangnya pemahaman masyarakat akan pola ruang natah yang baik sesuai dengan konsep filosofi budaya Bali. Penanggulangan yang perlu dilakukan agar masyarakat mengetahui tentang pengaplikasian konsep Asta Dala sebagai acuan penempatan tanaman adalah perlu diadakannya penyuluhan, sesuai penelitian ini, sebanyak $96 \%$ masyarakat setuju agar diberi penyuluhan.

Fungsi tanaman berdarsarkan konsep Asta Dala menunjukan sebanyak 87\% masyarakat Desa Sibang Gede menyatakan tidak mengetahui fungsi dari tanaman sesuai konsep filosofi budaya Bali, sedangkan sebanyak $13 \%$ masyarakat menyatakan mengetahui fungsi dari masing-masing tanaman sesuai dengan konsep filosfi budaya Bali. Banyaknya masyarakat menyatakan tidak mengetahui fungsi tanaman sesuai dengan konsep Asta Dala karena minimnya pemahaman masyarakat mengenai fungsi tanaman sesuai dengan konsep filosofi budaya Bali, hal tersebut akan membuat pola ruang natah yang sesuai dengan konsep filosofi budaya Bali tidak teraplikasikan dengan baik.

\subsection{Fungsi Tanaman Dalam Arsitektur Lansekap}

Tanaman memiliki fungsi yang beragam dalam lansekap, yaitu tanaman sebagai kontrol pandangan, apotek hidup atau tanaman obat keluarga, peneduh, dan nilai estetika (Hakim dan Utomo, 2003). Tanaman sebagai kontrol pandangan merupakan tanaman yang digunakan sebagai penghalang untuk kegiatan yang bersifat pribadi, sesuai dengan konsep Asta Dala, tanaman pengontrol pandangan dapat diletakan di arah timur pada natah sesuai dengan warna pada bunga tanaman tersebut. Tanaman sebagai apotek hidup atau tanaman obat keluarga merupakan tanaman yang digunakan sebagai bahan baku obat alami ataupun bahan untuk memasak oleh masyarakat yang khusus ditanam pada areal rumah, sesuai dengan konsep Asta Dala, tanaman sebagai apotek hidup dan tanaman obat keluarga dapat diletakan di arah selatan pada natah sesuai dengan warna pada bunga dan buah tanaman tersebut. Tanaman sebagai peneduh merupakan tanaman 
yang berfungsi sebagai penghalang masuknya sinar matahari atau lampu secara langsung ke dalam suatu obyek dalam taman, sesuai dengan konsep Asta Dala, tanaman peneduh dapat diletakan di arah barat pada natah sesuai dengan warna pada bunga, daun dan buah tanaman tersebut. Tanaman sebagai estetika merupakan tanaman yang berwujud untuk memperlihatkan ciri khas alami dari suatu taman dan terlihat tidak kaku, sesuai dengan konsep Asta Dala, tanaman sebagai estetika dapat diletakan di arah utara pada natah sesuai dengan warna pada bunga, daun, batang dan buah tanaman tersebut.

\subsection{Rekomendasi Untuk Menghasilkan Pola Ruang Natah Berdasarkan Konsep Filosofi Budaya Bali}

Rekomendasi yang dapat dilakukan untuk pencapaian pola ruang natah yang baik sesuai dengan konsep filosofi budaya Bali adalah harus berdasarkan pada konsep Asta Bumi dan Hulu-teben sebagai acuan untuk bangunan dan pengaplikasian konsep Asta Dala sebagai acuan dalam melakukan penempatan tanaman. Penggunaan konsep Tri Angga dan konsep akasa-pertiwi juga merupakan rekomendasi yang dapat dilakukan untuk pembuatan rumah bertingkat yang bertujuan untuk menghindari perubahan sikut natah yang sudah ada sejak dulu berdasarkan konsep filosofi budaya Bali. Bangunan yang boleh ditingkatkan adalah bukan untuk semua bangunan dari pada rumah tradisional Bali, melainkan salah satu bangunan, yaitu bale delod dikarenakan bale daja, bale dauh dan bale dangin merupakan bale dasar dan juga merupakan bale suci yang dipergunakan untuk pelaksanaan upacara Yadnya. Rekomendasi untuk menghasilkan pola ruang natah berdasrkan konsep filosofi budaya bali dapat dilihat pada Gambar 1 berikut:

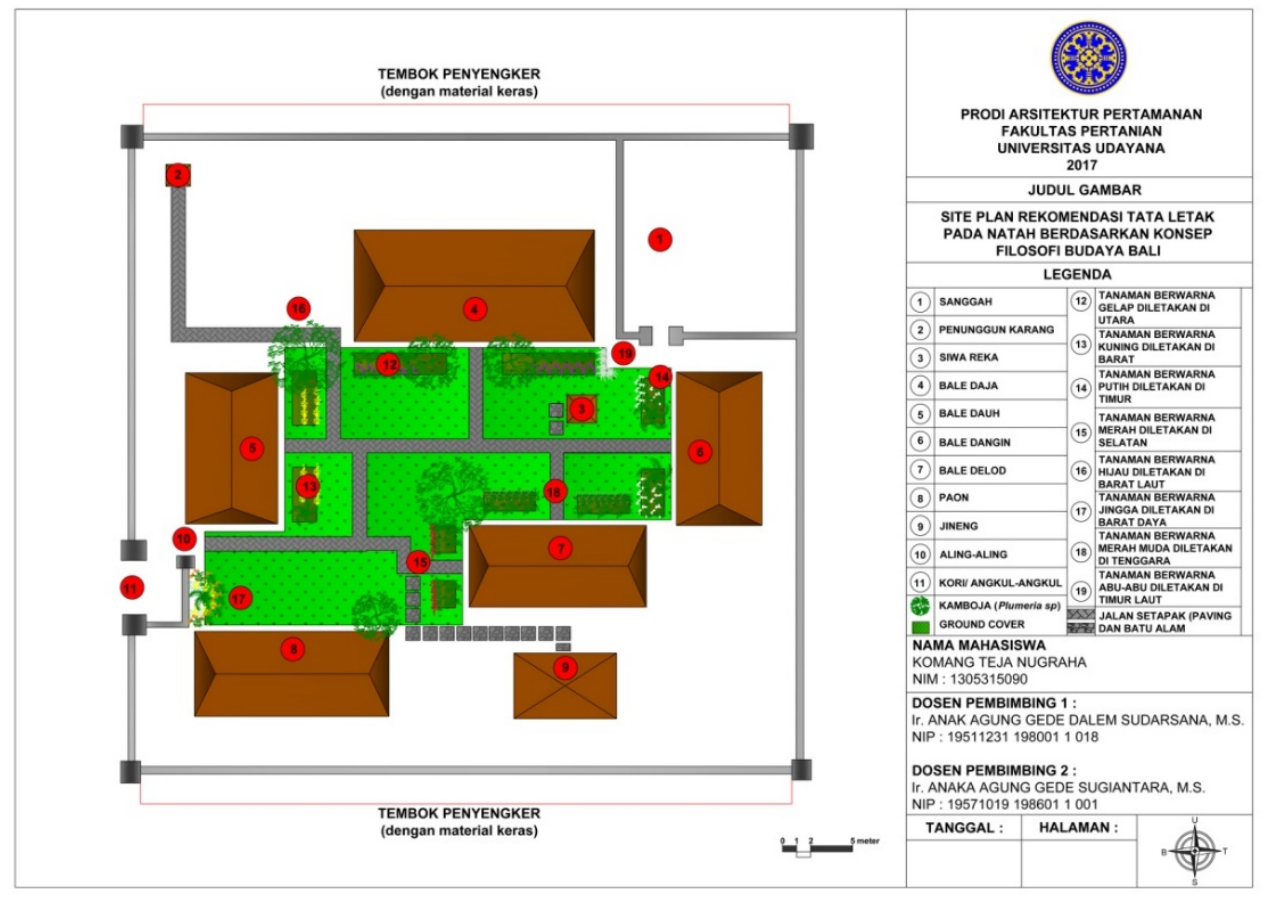

Gambar 1. Rekomendasi Pola Ruang Natah Berdasarkan Konsep Filosofi Budaya Bali

\section{Simpulan}

Masih banyaknya masyarakat Desa Sibang Gede yang belum mengetahui tentang penempatan tata letak dan jarak dari bangunan. Sebanyak $60 \%$ masyarakat menyatakan tidak mengetahui dan sebanyak $40 \%$ masyarakat mengetahui tentang penempatan tata letak dan jarak dari bangunan sesuai dengan konsep filosofi budaya Bali. Terdapat satu perbedaan fungsi bangunan bale delod pada umumnya dengan bale delod yang berada di Desa Sibang Gede. Bale delod di Desa Sibang Gede digunakan untuk tempat upacara yadnya sedangkan untuk bale delod pada umumnya dipergunakan sebagai tempat tidur anggota keluarga, keunikan ini disebabkan oleh budaya dan adat-istiadat yang sudah ada sejak dulu dan perlu dipertahankan dikerenakan memiliki keunikan tersendiri. Masih banyaknya masyarakat Desa Sibang Gede yang belum mengaplikasikan konsep Asta Dala dalam penempatan tanaman, sebanyak 98\% masyarakat tidak mengaplikasikan dan sebanyak 2\% masyarakat mengaplikasikan konsep Asta Dala tersebut. Terdapat rekomendasi yang dilakukan 
untuk pencapaian pola ruang natah berdasarkan konsep filosofi budaya Bali dengan mengaplikasikan konsep Asta Bumi dan Hulu-teben untuk tata letak bangunan serta konsep Asta Dala untuk tata letak tanaman.

\section{Daftar Pustaka}

Ayadnya, S. I. B. dan I. B. K Arinasa. 2004. "Peranan Wariga terhadap Penggunaan Tanaman Upacara Adat". Seminar Tumbuhan Upacara Agama Hindu, UPT BKT Kebun Raya "Eka Karya" Bali - LIPI.

Bidja, I Made. 2000. "Asta Kosala-Kosali dan Asta Bumi". PT. Empat Warna Komunikasi. Denpasar.

Dwijendra, Achwin Ngakan Ketut. 2008. Arsitektur Rumah Tradisional Bali. Udayana University Press. Denpasar.

Hakim, R. dan H. Utomo. 2003. Komponen Perancangan Arsitektur Lansekap: Prinsip-unsur dan Aplikasi. Bumi Aksara. Jakarta.

Morissan, M. A. 2012. Metode Penelitian Survei. Kencana. Jakarta.

Pemerintah Desa Sibang Gede. 2016. Data Desa Sibang Gede. Kantor Desa Sibang Gede. Badung.

Pemerintah Desa Sibang Gede. 2016. Monografi Desa Sibang Gede. Kantor Desa Sibang Gede. Badung.

Pulasari, Jro Mangku, Jro Mangku Sampun Widaryana, Jro Mangku Suahta Santy, Jro Mangku Nyoman Artana. 2015. Cakepan Asta Kosala-Kosali lan Asta Bhumi. Paramita. Denpasar.

Raharja, Gede Mugi. 2005. "Taman Tradisional Bali" Bali Post. Tersedia online: http://www.balipost.co.id/BALIPOSTCETAK/2005/10/2/des1.html. (diakses 05 Juni 2017).

Sardiana, I. K., Wayan P. Windia, I.G.N. Sudiana, Sundani N. Soewandhi, Ketut Sundra, Wayan Sudarka, Made Widnyana Sudibya, Ketut Kartha Dinata, Sang Made Sarwadana, Wayan Sukersa. 2010. Taman Gumi Banten: Ensiklopedia Tanaman Upakara. Udayana University Press. Denpasar.

Silalahi, U. 2006. Metode Penelitian Sosial. Unpar Press. Bandung.

Suarya, I Made. 2003. Peranan Natah di Dalam Kehidupan Masyarakat Bali. Jurnal Fakultas Teknik, Vol. 1 No.1-Februari 2003: 1-7. Universitas Udayana. Denpasar.

Sudjana, D. 2001. Metode Statistika. Tarsito. Bandung.

Sugiyono, D. 2004. Metode Penelitian Bisnis. CV. Alfabeta. Bandung.

Tuman, 2001. Overview of GIS. Tersedia secara online di: www.gisdevelopment.net. (diakses 15 Juni 2017). 